\title{
Positive attitudes towards priority setting in clinical guidelines among Danish general practitioners: A web based survey
}

\author{
Ann Nielsen ${ }^{1}$, Benedicte Carlsen $^{2 *}$, Pia K. Kjellberg ${ }^{1}$ \\ ${ }^{1}$ KORA - Danish Institute for Local and Regional Government Research, Copenhagen, Denmark \\ ${ }^{2}$ Uni Rokkan Centre, Uni Research, Bergen, Norway; ${ }^{*}$ Corresponding Author: benedicte.carlsen@uni.no
}

Received 4 January 2013; revised 3 February 2013; accepted 10 February 2013

\section{ABSTRACT}

Aims: Increasing focus on improvement and optimisation of the treatment in primary care and reduction of healthcare costs emphasize the need to understand which factors determines adherence and non-adherence to clinical guidelines. In the present study, we examined attitudes towards clinical guidelines in Danish general practitioners (GPs). Methods: We conducted a survey among Danish GPs from all five regions of Denmark. In total, 443 GPs answered the web-based questionnaire that contained questions about attitudes and barriers to clinical guidelines. Results: More than $90 \%$ of the GPs reported that they have good knowledge of the guidelines and in general follows the guidelines. A majority of the GPs (81\%) found it acceptable that economic considerations are part of the guidelines. The most important factors for nonadherence to guidelines were "need of adjustment to clinical practice" and "lack of confidence in guidelines". The attitudes to clinical guidelines were not significantly associated with practice characteristics such as gender, years of experience, practice organisation and localisation. Conclusions: Our findings show that clinical guidelines are an integrated or internalised part of everyday practice among GPs in Denmark. Furthermore, the findings indicate that Danish GPs are positive towards applying priority setting in their practice. This is decisive in the light of rising healthcare costs due to development of new expensive technologies and ageing populations that puts pressure on the healthcare system in general and primary healthcare in particular.

Keywords: Clinical Guidelines; General
Practitioners; Adherence; Attitudes; Barriers

\section{INTRODUCTION}

The definition of clinical practice guidelines is "systematically developed statements to assist practitioner and patient decisions about appropriate healthcare for specific clinical circumstances" [1].

Francke et al. conducted in 2008 a meta-review to understand which factors that affect the implementation of guidelines [2]. Based on twelve reviews and metaanalyses the key restraints for following clinical guidelines were: complexity of the guideline, accessibility, lack of confidence in guidelines, and time constraints. Easily understood guidelines and guidelines developed by the target group or end users were more likely to be implemented. Lack of awareness of guideline and lack of agreement with guideline reduced likelihood of implementation and limited time and personnel resources as well as work pressure also made implementation less likely [2].

In 2010, the Danish Medical Association conducted a survey about use of clinical guidelines among 1675 clinicians within a wide range of specialties. The study showed that format, accessibility and appropriate implementation strategies are crucial to successful implementation and use of clinical guidelines among clinicians. In 2008 , we conducted a qualitative interview study among 18 Danish GPs from the capital area, which showed similar trends [3]. The views that emerged from this study were that GPs found it difficult to keep updated on new treatments and research evidence and some of the GPs expressed that they missed a single comprehensive source of guidelines. Another key finding was that the GPs sometimes experienced a dilemma between standardisation practice and individual treatment of the patient. But most importantly the study revealed that Danish GPs have a positive attitude towards inclusion of economic considerations and priority setting through the 
guidelines [3].

In Denmark there is a fairly long history of issuing clinical guidelines. Clinical guidelines targeting GPs has since the 1980s been issued by The Danish College of General Practitioners, The national Board of Health and since 1999 the Institute for Rational Pharmacotherapy $[6,13]$. Internationally there has also been an increasing focus on optimising the treatment in primary care and reduction of healthcare costs. In England, NICE (National Institute for Clinical Excellence) was established to develop, disseminate and implement guidelines on a range of clinical activities [4,5]. Large amounts of resources are used continuously to develop new guidelines and update existing guidelines within the field of primary care. Thus knowledge about adherence and non-adherence to clinical guidelines are of interest from a clinical and a political point of view. To gain broader understanding of the attitudes towards clinical guideline in a Danish setting and to update our knowledge of barriers to implementation of guidelines, we conducted a survey among GPs located in all five regions of Denmark.

\section{METHODS}

The survey was carried out in March 2011. An invitation letter with a link to the web-based questionnaire was e-mailed to all general practitioners (GP) in Denmark (n $=3649$ ) in March 2011. One reminder was distributed and the link was open for two weeks. Responding to the invitation was possible through the received link to the web. In all, 487 GPs responded to the invitation. Of those, 10 GPs refused to participate and 34 did not answer the questions regarding attitudes and barriers to clinical guidelines, leaving us with a study population of 443 Danish GPs.

The questionnaire was developed in close cooperation with Norwegian researchers as the survey was carried out in both countries. Details on the questionnaire have been described previously [7]. Briefly, the questionnaire was composed of two parts, namely the clinical guidelines questions and a discrete choice experiment (DCE). The DCE is not included in the present study, but will be reported later. In the guideline section the GPs were asked about attitudes and barriers to guidelines. All the questions were asked as statements to which the GP, by use of a four-point Likert scale, could express the extent of their agreement (completely and partly agree/disagree) or in the case of barriers to guidelines, the importance of the statement (not, slightly, fairly or very important). The questions included were based on the findings from previous international reviews [8-11] and from a comparative interview study carried out among 45 Danish and Norwegian GPs $[3,12]$. In addition, we added questions regarding GP and practice characteristics in the Danish survey (e.g. practice organization, GPs age, gender and years since graduation). The questionnaire was further validated in a Danish context by testing the questionnaire among a couple of GPs and among persons with knowledge about survey methodology.

\section{Statistical Analyses}

We estimated the proportions of GPs who agreed with the attitudes or barriers to guidelines. Furthermore associations between adherence and attitudes to guidelines and practice characteristics were assessed in univariate logistic regression models (STATA 10.1). Practice characteristics were organisation of the practice (singlehanded, partnership), localisation (region of Denmark), and characteristics of the GP (gender and years since graduation).

The measure of association was the odds ratio (OR) with the corresponding $95 \%$ confidence interval (CI).

\section{RESULTS}

The mean age of the GPs was 52 years (range 32 - 75 years) and $42 \%$ were men. We do not have comparable data on the age of all Danish GPs. The gender distribution was, however, the same among the participating GPs $(\mathrm{p}=0.99)$ as among the invited population [17]. The mean number of years since graduation was 24 years (range 5 - 45 years). The female GPs had slightly fewer years of experience compared with their male colleagues (women; 21 years vs. men; 25 years). The proportion of GPs from single-handed practices was $17 \%$, whereas the remaining GPs were part of partnerships practices or shared single-handed practices. The GPs represented the entire country with one third being located in the Capital. The distribution were as follows; Capital: $33 \%$, Zealand: $19 \%$, North: $8 \%$, Central: $18 \%$, South: $22 \%$. This distribution was, however, slightly different from the invited participants where the distribution was the following; capital: $35 \%$, Zealand: $17 \%$, North $11 \%$, Central: $10 \%$, South: $27 \%(\mathrm{p}<0.01)$.

The attitudes and adherence to clinical guidelines among the study population are shown in Table 1. In general the GPs are positive to clinical guidelines. The majority of the GPs report, that they have good knowledge of the guidelines (93.2\%) and have confidence in guidelines from the health authorities $(88.9 \%)$ and the Danish medical societies (88.3\%). A significantly lower proportion have confidence in guidelines from the pharmaceutical industry (13.8\%). In general, the GPs claim that they follow the guidelines $(95.7 \%)$ and only a minor proportion see guidelines as a threat to their professional work (17.2\%). A majority of the GPs find it acceptable that economic considerations are part of the guidelines, as long as they are informed about it (80.8\%).

Table 2 display different reasons for non-adherence to 
Table 1. Attitudes and adherence to guidelines among Danish GPs $(n=443)$.

\begin{tabular}{|c|c|c|}
\hline & \multicolumn{2}{|c|}{$\begin{array}{l}\text { Partly or } \\
\text { totally agree }\end{array}$} \\
\hline & $\mathrm{n}$ & $(\%)$ \\
\hline I have good knowledge of guidelines in my specialty & 413 & $(93.2)$ \\
\hline $\begin{array}{l}\text { I have confidence in guidelines from the health } \\
\text { authorities }\end{array}$ & 394 & (88.9) \\
\hline $\begin{array}{l}\text { I have confidence in guidelines from the Danish } \\
\text { Medical Societies }\end{array}$ & 391 & (88.3) \\
\hline $\begin{array}{l}\text { I have confidence in guidelines from the } \\
\text { pharmaceutical industry }\end{array}$ & 61 & $(13.8)$ \\
\hline $\begin{array}{l}\text { Guidelines pose a threat to my professional } \\
\text { judgment/autonomy }\end{array}$ & 76 & $(17.2)$ \\
\hline Generally, I follow the guidelines & 424 & $(95.7)$ \\
\hline $\begin{array}{l}\text { The guidelines are integrated in my practice, I do } \\
\text { not need to look them up }\end{array}$ & 284 & $(64.1)$ \\
\hline $\begin{array}{l}\text { Inclusion of economic considerations are acceptable, } \\
\text { if it is stated in the guideline }\end{array}$ & 358 & $(80.8)$ \\
\hline
\end{tabular}

Table 2. Barriers to use of clinical guidelines $(n=443)$.

\begin{tabular}{lccc}
\hline & \multicolumn{2}{c}{$\begin{array}{c}\text { Fairly or very } \\
\text { important }\end{array}$} \\
\cline { 2 - 4 } & $\mathrm{n}$ & $(\%)$ \\
\hline Economic factors & & \\
Guidelines are driven by economic incentives & 154 & $(34.8)$ \\
Guidelines are driven by the government cost-savings & 174 & $(39.3)$ \\
$\begin{array}{l}\text { Economic concerns overshadow clinical concerns } \\
\text { Time factors }\end{array}$ & & 25.3 \\
$\begin{array}{l}\text { Guidelines are bothersome or time consuming to } \\
\text { get hold of }\end{array}$ & 185 & $(41.8)$ \\
$\begin{array}{l}\text { Cannot spend time negotiating with the patient } \\
\text { only to follow a guideline }\end{array}$ & 109 & $(24.6)$ \\
$\begin{array}{l}\text { Do not have the time to update on new guidelines } \\
\text { Evidence }\end{array}$ & 128 & $(28.9)$ \\
Sceptical about the evidence & & \\
$\begin{array}{l}\text { Disagree frequently with the recommendations of } \\
\text { the guidelines }\end{array}$ & 200 & $(42.2)$ \\
$\begin{array}{l}\text { Guidelines are only suggestions, clinical judgment } \\
\text { should be applied }\end{array}$ & 285 & $(16.3)$ \\
Patient perspective & & \\
Guidelines does not fit the individual patient & 219 & $(49.3)$ \\
$\begin{array}{l}\text { The recommendation is contrary to the patients } \\
\text { preferences }\end{array}$ & 172 & $(38.8)$ \\
\hline
\end{tabular}

guidelines. The barriers most frequently rated as fairly or very important for non-adherence were related to the need for adjustment to clinical practice and to the lack of confidence in guidelines. Thus the three most important factors mentioned were as follows; "guidelines are only suggestions, clinical judgment should be applied" (64.3\%), "guidelines does not fit the individual patient" (49.4\%) and "I am sceptical about the evidence" (45.2\%). However, the statements do not provide us with information about how often non-adherence to guidelines occurs.

In Table 3, we examine the associations between different GP and practice characteristics and adherence and attitudes towards guidelines. We examined whether adherence and attitudes to clinical guidelines were associated with the following GP and practice characteristics: gender of the GP, years since graduation, practice organisation and localisation. The most experienced GPs tended to be more likely to follow guidelines compared with less experienced colleagues. Furthermore, GPs outside the capital area was not as likely to follow the guidelines as GPs from the capital area. However, none of these tendencies were statistically significant. GPs outside the capital area were less likely to find economic considerations acceptable in guidelines. Particularly, GPs from Region South were less likely to accept economic considerations.

Table 3. Associations between GP and practice characteristics and adherence and attitudes towards guidelines.

\begin{tabular}{|c|c|c|c|c|}
\hline & \multicolumn{2}{|c|}{$\begin{array}{l}\text { Generally. follow the } \\
\text { guidelines }\end{array}$} & \multicolumn{2}{|c|}{$\begin{array}{c}\text { Economic } \\
\text { considerations are } \\
\text { acceptable. if stated } \\
\text { in the guideline }\end{array}$} \\
\hline & $\mathrm{OR}^{*}$ & $95 \% \mathrm{CI}$ & $\mathrm{OR}^{*}$ & $95 \% \mathrm{CI}$ \\
\hline \multicolumn{5}{|l|}{ Gender } \\
\hline Women & 1.00 & ref. & 1.00 & ref. \\
\hline Men & 0.67 & $0.25-1.82$ & 1.45 & $0.88-2.39$ \\
\hline \multicolumn{5}{|l|}{ Years since graduation } \\
\hline$<10$ & 1.00 & ref. & 1.00 & ref. \\
\hline $11-15$ & 1.11 & $0.20-6.07$ & 0.81 & $0.24-2.73$ \\
\hline $16-20$ & 1.98 & $0.31-12.46$ & 0.70 & $0.21-2.33$ \\
\hline $21-25$ & 2.15 & $0.29-16.07$ & 0.63 & $0.18-2.15$ \\
\hline$\geq 26$ & 2.27 & $0.44-11.83$ & 0.77 & $0.25-2.36$ \\
\hline \multicolumn{5}{|l|}{ Practice organisation } \\
\hline Single-handed & 1.00 & ref. & 1.00 & ref. \\
\hline Partnership & 1.50 & $0.46-4.83$ & 0.82 & $0.40-1.66$ \\
\hline $\begin{array}{l}\text { Shared/group of single- } \\
\text { handed }\end{array}$ & 0.62 & $0.13-2.93$ & 0.53 & $0.20-1.43$ \\
\hline Combination & - & & 1.42 & $0.36-5.53$ \\
\hline \multicolumn{5}{|l|}{ Region } \\
\hline The capital & 1.00 & ref. & 1.00 & ref. \\
\hline Zealand & 0.23 & $0.04-1.20$ & 0.63 & $0.30-1.31$ \\
\hline North & 0.47 & $0.04-5.32$ & 0.68 & $0.25-1.86$ \\
\hline Central & 0.28 & $0.05-1.54$ & 0.67 & $0.32-1.44$ \\
\hline South & 0.22 & $0.04-1.10$ & 0.48 & $0.24-0.94$ \\
\hline
\end{tabular}

${ }^{*}$ Crude odds ratio. 
Finally, we examined, whether barriers to guidelines were associated with the above mentioned practice characteristics, but no associations were found between practice characteristics and barriers to use of guidelines (data not shown).

\section{DISCUSSION}

In our study, we find generally positive attitudes towards guidelines. The vast majority of the GPs report that they use guidelines is well aware of the guidelines, and have confidence in guidelines from the government and the medical societies. These findings indicate that clinical guidelines are an integrated or internalised part of the everyday practice among GPs in Denmark.

Also a previous study finds that the majority of Danish GPs use clinical guidelines [14]. In an international perspective, a review by Farquhar et al. concluded, that GPs and other healthcare professionals are very satisfied with guidelines [10]. However, in studies where use of specific guidelines have been examined guideline adherence has not necessarily corresponded with the revealed general attitudes towards guidelines [2]. In a Norwegian study, GPs were asked about their knowledge of specific guidelines and their use of the same guidelines [15]. The study revealed that in most situations the knowledge of the guideline was substantially greater than the actual use of the guideline.

Maybe more surprisingly, we found that the majority of Danish GPs agree with the statement that economic considerations or incentives may be incorporated in the guidelines as long as it is stated in the guideline. This view is more positive than what earlier studies generally show; a qualitative meta-study of international studies on GPs' attitudes to guidelines found that doctors often express scepticism to elements of cost containment in clinical guidelines [20]. On the other hand, our finding supports previous findings from the interview study conducted in 2008 among eighteen GPs in the Copenhagen area [3]. In the interviews the GPs described that they accepted economic considerations as long as they were transparent to the healthcare professional. Findings from Norwegian GPs in the same study showed a markedly more sceptical view on economic considerations and priority setting in Norwegian GPs [3].

Another key factor that supports Danish GPs integration of clinical guidelines in practice is the high proportion of GPs that see clinical guidelines as suggestions to which clinical judgment should be applied. In the late 1990's Woolf et al. described clinical guidelines as only one option for improving the quality of care [16]. They described guidelines as useful in situations where clinicians are uncertain about the treatment, or as a tool to reassure clinicians about the appropriateness of their treatment and to improve the consistency of care [16]. In this perspective clinical judgment of the individual patient is important to take into account in the daily use of clinical guidelines and our findings indicate that this practice is implemented among the majority of GPs in Denmark.

Finally, we revealed no significant associations between GP and practice characteristics and adherence and attitudes to guidelines. Beforehand, we tended to expect that more experienced GPs and GPs in single-handed practices may be less likely to adhere to guidelines and may be more sceptical about economic considerations. Our results, however, did not support these hypotheses.

Some strengths and limitations of the study merit discussion. We decided to conduct a web-based survey as opposed to a postal survey because of the easy and low cost distribution and attainment of responses. In addition, methodological studies indicate that web based surveys yield better quality data in terms of less missing and nonsense responses [18]. However, web-surveys are frequently limited by low response rates, and so also in our study, which had a response rate of $13 \%$. Still, this is within the range of published studies based on Internetsurveys with health professionals [19], and the results show that the study group profile is quite similar to the whole population of GPs in Denmark according to the observable characteristics.

The GPs participating must be considered as being highly motivated as they received no compensation for participation in the study. Being highly motivated or interested in the on-going debate about clinical guidelines may, have facilitated GPs with strong opinions about clinical guidelines to participate. On the other hands, our findings are largely in line with previous findings in Denmark as well as in settings outside Denmark, indicating that the participating GPs largely represent the attitudes in GPs in general.

A potential strength of our study is the inclusion of questions about several aspects of barriers for implementation of guidelines. According to the review by $\mathrm{Ca}-$ bana et al. only a few studies have considered the variety of barriers that influence the implementation of clinical guidelines. Most studies have rather focused on a few specific barriers [8]. Cabana divides barriers into different categories related to knowledge, attitudes and behaviour. In our study aspects from all three groups of barriers have been considered, which may have ensured a more profound examination of perceived barriers to guidelines among Danish GPs.

In summary, we observed that Danish GPs perceive clinical guideline as an integrated part of their everyday practice and have great confidence in guidelines from the Danish health authorities. Danish GPs also find that as long as there is transparency, it is acceptable to incorporate economic incentives in the guidelines. This under- 
lines that Danish GPs are accustomed to apply priority setting in their everyday practice and see clinical guidelines as a part of this paradigm, a paradigm, that recently has been debated extensively, as there in the future will be rising health care costs due to development of more expensive technologies and ageing populations. More elderly and more chronically ill patients with an increased need of treatment, put pressure on the healthcare system in general and on primary healthcare in particular.

\section{FUNDING ACKNOWLEDGEMENTS}

The study has received funding from DSI, Danish Institute for Health Services Research, Copenhagen and The Research Council of Norway (Grant number 196311).

\section{REFERENCES}

[1] Field, M. (1990) Attributes of good practice guidelines. In: Clinical Practice Guidelines: Directions for a New Program, National Academy Press, Washington DC, 53-77.

[2] Francke, A.L., Smit, M.C., de Veer, A.J., et al. (2008) Factors influencing the implementation of clinical guidelines for health care professionals: A systematic meta-review. BMC Medical Informatics and Decision Making, 8, 38. doi:10.1186/1472-6947-8-38

[3] Carlsen, B. and Kjellberg, P.K. (2010) Guidelines; from foe to friend? Comparative interviews with GPs in Norway and Denmark. BMC Health Service Research, 10, 17. doi:10.1186/1472-6963-10-17

[4] Jones, R., Dowie, R. and Robinson, M. (2000) Guidelines implementation and research in the future. Family Practice, 17, 36-37. doi:10.1093/fampra/17.suppl_1.S36

[5] Dowie, R., Robinson, M. and Jones, R. (2000) Research on guidelines implementation in primary care. Introduction. Family Practice, 17, 1-2. doi:10.1093/fampra/17.suppl 1.S1

[6] The Danish College of General Practitioners (1996) Kliniske vejledninger $\mathrm{i}$ almen medicin [Clinical guidelines in general practice]. DSAM, Copenhagen.

[7] Carlsen, B. and Bringedal, B. (2011) Attitudes to clinical guidelines-Do GPs differ from other medical doctors? BMJ Quality and Safety, 20, 158-162. doi:10.1136/bmjqs.2009.034249

[8] Cabana, M.D., Rand, C.S., Powe, N.R., et al. (1999) Why don't physicians follow clinical practice guidelines? A framework for improvement. Journal of the American
Medical Association, 282, 1458-1465. doi:10.1001/jama.282.15.1458

[9] Carlsen, B., Glenton, C. and Pope, C. (2007) Thou shalt versus thou shalt not: A meta-synthesis of GPs' attitudes to clinical practice guidelines. British Journal of General Practice, 57, 971-978. doi:10.3399/096016407782604820

[10] Farquhar, C.M., Kofa, E.W. and Slutsky, J.R. (2002) Clinicians' attitudes to clinical practice guidelines: A systematic review. Medical Journal of Australia, 177, 502-506.

[11] Grimshaw, J., Eccles, M. and Tetroe, J. (2004) Implementing clinical guidelines: Current evidence and future implications. Journal of Continuing Education in the Health Professions, 24, S31-S37. doi:10.1002/chp.1340240506

[12] Carlsen, B. and Norheim, O.F. (2008) "What lies beneath it all?"-An interview study of GPs' attitudes to the use of guidelines. BMC Health Service Research, 8, 218. doi:10.1186/1472-6963-8-218

[13] Institute for rational pharmacotherapy (2011). http://www.irf.dk/dk/om_irf/irfs_historie/

[14] Danish Medical Association (2010) Doctors use of clinical guidelines [Sådan bruger læger kliniske retningslinjer].

[15] Treweek, S., Flottorp, S., Fretheim, A., et al. (2005) Guidelines in general practice-Are they read and are they used? Tidsskrift for Den norske Laegeforening, 125, 300-303.

[16] Woolf, S.H., Grol, R., Hutchinson, A., et al. (1999) Clinical guidelines: Potential benefits, limitations, and harms of clinical guidelines. British Medical Journal, 318, 527 530. doi:10.1136/bmj.318.7182.527

[17] Organisation of general practitioners in Denmark (2011). http://www.laeger.dk/portal/page/portal/LAEGERDK/Lae gerdk/P_L_O/Om\%20PLO/Tal\%20og\%20publikationer/ Statistik $\% 20$ om $\% 20$ almen $\% 20$ praksis/praksist $\%$ C3\%A61 ling_2009.pdf

[18] Matteson, K.A., Anderson, B.L., Pinto, S.B., Lopes, V., Schulkin, J. and Clark, M.A. (2011) Surveying ourselves: Examining the use of a web-based approach for a physician survey. Evaluation \& the Health Professions, 34, 448463. doi:10.1177/0163278710391086

[19] Braithwaite, D., Emery, J., de Lusignan, S. and Sutton, S. (2003) Using the internet to conduct surveys of health professionals: A valid alternative? Family Practice, 20, 545-551. doi:10.1093/fampra/cmg509

[20] Carlsen, B., Glenton, C. and Pope, C. (2007) Thou shalt versus thou shalt not. A qualitative meta-synthesis of GPs' attitudes to clinical practice guidelines. British Journal of General Practice, 57, 971-978. doi: $10.3399 / 096016407782604820$ 